\title{
Mechanical and Wear Properties of Cold Extruded Al6063 Metal Matrix Alloy Reinforced with Silicon Carbide, Alumina and Cerium Oxide
}

\author{
Abdul Nazeer, Mir Safiulla
}

\begin{abstract}
Metal matrix composite is considered in various engineering fields like Automobile, medical, electronics aerospace, marine, recreational sectors, of which Aluminum metal matrix composite is considered mostly because of its high strength to weight ratio, easy of fabrication, corrosion resistance, good aesthetic appearance and high resistance to wear etc. This paper concentrates on the effect of secondary processing (Cold Extrusion) on mechanical and wear properties of Al6063 reinforced with $\mathrm{SiC}, \mathrm{Al}_{2} \mathrm{O}_{3}$ and $\mathrm{CeO}_{2}$ particles. Here composite systems prepared by varying reinforcement from $0 \%$ to $8 \%$ in steps of $2 \%$. Stir casting route adopted for casting composite systems after casting the composite is made to pass through extrusion process with an extrusion ratio of 1.93 with a total strain of 1.45 . All composite systems tested for mechanical properties as per ASTM and ISO standard. Wear test was conducted on pin on disc setup for different loads, reinforcement, sliding distance and sliding speed. Results reveals that due increase in reinforcement the mechanical properties have improved further improvement observed when subjected to extrusion process, similar observation was made for wear studies which conclude the wear rate is improved for extruded composite as compared to cast composite systems observed by various researchers.
\end{abstract}

Keywords: Aluminum 6063 matrix composite, Silicon Carbide, Stir Casting, Pin on disc and Mechanical Tests.

\section{INTRODUCTION}

Metal matrix composite have replaced many conventional materials due to its superior properties light weight with good resistance to corrosion and wear, due to these properties this materials are widely accepted in many engineering sectors like Marnie, Aerospace, Electrical, Automobile etc. Aluminum matrix composite have universally accepted due to its excellent friction and wear resistance, good corrosion resistance high elastic modulus, high specific strength, low coefficient to thermal expansion. Particulate reinforced metal matrix composite has widely accepted in last few decades, addition of ceramic particles in aluminum alloy has

Revised Manuscript Received on February 05, 2020.

* Correspondence Author

Abdul Nazeer*, Research Scholar, Department of Mechanical Engineering, Ghousia college of Engineering, Visvesvaraya Technological University, Balgavi, Karnataka, India. Email: nazeer0301@gmail.com

Mir Safiulla, Professor \& Principal, Islamiah Institute of Technology, Bangalore, Visvesvaraya Technological University, Balgavi, Karnataka, India.

(C) The Authors. Published by Blue Eyes Intelligence Engineering and Sciences Publication (BEIESP). This is an open access article under the CC BY-NC-ND license (http://creativecommons.org/licenses/by-nc-nd/4.0/) significantly improved mechanical and wear properties., the major problem associated with fabrication of metal matrix reinforcing with ceramic particles was poor wettability due to which agglomeration of reinforcement formed, the issue overcome with the development of different production techniques also optimizing the different production technique helps to fulfill the industry requirement at larger extent[18]. In liquid metallurgy route stir casting technique is widely used due to its easy of production and economical [17]. The present trends of potential applications is to improve the temperature effect, tribological properties and mechanical properties. Researchers identified number of reinforcement for aluminum based metal matrix composite like $\mathrm{TiB}_{2}, \mathrm{SiC}$, $\mathrm{TiO}_{2}, \mathrm{Al}_{2} \mathrm{O}_{3}, \mathrm{TiC}, \mathrm{Gr}$ to improve the properties of composite $[4,6,7]$.It is also found that with reinforcing the fly ash with $5 \%$ and $10 \%$ by weight in Al6063 Hardness, Tensile and wear properties have improved [2].

Hybrid composite have also made a greater impact to replace the conventional materials. Reinforcement like SiC/Gr a hybrid reinforcement in aluminum matrix have improved significantly the tensile strength and reinforcement are evenly distributed as resulted [1].

Aluminium Based Silicon Carbide Particulate Metal Matrix Composite has identified for power transmitting product like manufacturing of Spur Gear [3], Aluminium composite systems exhibits good wear and friction properties when proper proportion of reinforcement added [7].

Researcher worked to study the effect of particle size which made them to involve with reinforcing the nanoparticles in multiwall carbon nanotubes [11] which resulted a very good output but the process of fabrication is very tedious and very expensive. A lot of work on primary processed composite done with various combination researcher are now focused on secondary processing of primary processed composite, it has found larger difference in hardness was observed at the surface compared to the core area due to severe deformation that occurred at the dead metal zone surface during extrusion. [16] Due to extrusion process the grain refinement improves which in turns improve the mechanical properties of composite [5].

The present work aims to study the effect of secondary process (Cold extrusion) on mechanical and wear properties for aluminum matrix reinforced with $\mathrm{SiC}, \mathrm{Al}_{2} \mathrm{O}_{3}$ and $\mathrm{CeO}_{2}$ particles of varying weight percentage from $0 \%$ to $8 \%$ instep of $2 \%$. 


\section{EXPERIMENTAL PROCEDURE}

\section{A. Materials}

Aluminum 6063 is used as metal matrix, Silicon Carbide, Aluminium oxide and cerium oxide as reinforcement in lab grade powder form.

Table I: Composition of Al6063

\begin{tabular}{|c|c|c|c|c|c|c|}
\hline Elements & $\mathrm{Si}$ & $\mathbf{F e}$ & $\mathrm{Cu}$ & $\mathrm{Mn}$ & $\mathbf{M g}$ & $\mathrm{Al}$ \\
\hline$\%$ & $0.2 \%-$ & $0.35 \%$ & $0.10 \%$ & 0.8 & $0.10 \%$ & Balance \\
(max.) & $0.6 \%$ & 3 & 4 & & & \\
\hline
\end{tabular}

Table II: Mechanical properties of Matrix and reinforcement

\begin{tabular}{|l|c|c|c|c|}
\hline $\begin{array}{c}\text { Material/ } \\
\text { Propertie } \\
\text { s }\end{array}$ & $\begin{array}{c}\text { Densit } \\
\mathbf{y} \\
\text { gm/cc }\end{array}$ & $\begin{array}{c}\text { Hardne } \\
\text { ss }\end{array}$ & $\begin{array}{c}\text { Strength } \\
\text { (Tensile/ } \\
\text { Compressi } \\
\text { ve) (MPa) }\end{array}$ & $\begin{array}{c}\text { Elastic } \\
\text { modulus } \\
\text { (GPa) }\end{array}$ \\
\hline $\begin{array}{l}\text { Matrix } \\
\mathbf{6 0 6 3} \mathbf{A l}\end{array}$ & 2.7 & 73 & 130 & 68.9 \\
\hline $\mathbf{S i C}$ & 3.02 & 2800 & $3900(\mathrm{C})$ & 410 \\
\hline $\mathbf{A l}_{\mathbf{2}} \mathbf{O}_{3}$ & 3.9 & & $282-551$ & 380 \\
\hline $\mathbf{C e O}_{2}$ & 7.215 & & 155 & 180 \\
\hline
\end{tabular}

\section{B. Preparation of Composites}

Liquid metallurgy route stir casting technique adopted for preparation of Al6063- Sic, $\mathrm{Al}_{2} \mathrm{O}_{3}$ and $\mathrm{CeO}_{2}$ composite systems, reinforcement powder of lab grade is first preheated about $300^{\circ} \mathrm{C}$ and the molten matrix, which is maintained at a constant temperature of $700^{\circ} \mathrm{C}$, the reinforcement is induced $0-8 \%$ in steps of $2 \%$ and gradually mix in liquid matrix to a constant stirring time was $10 \mathrm{~min}$ for all set of composite. The prepared composite is poured in mould of predefined shape and size and kept for solidification process at room temperature. The cast specimen were machined to require dimensions. Fig 1a-1b shows the preparation of composite and prepared samples. Here the mould used for casting is made of cast iron and the tool used machining the specimen is High speed steel (HSS).

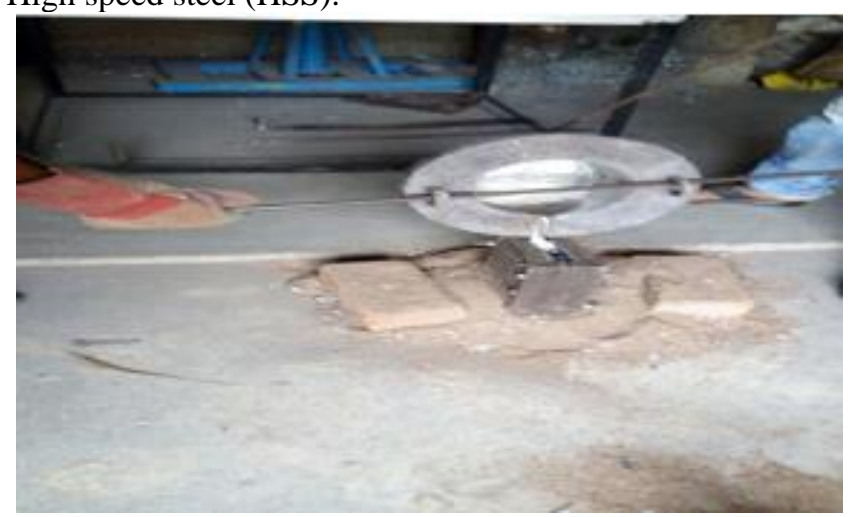

Fig 1.a Pouring of molten material into mold

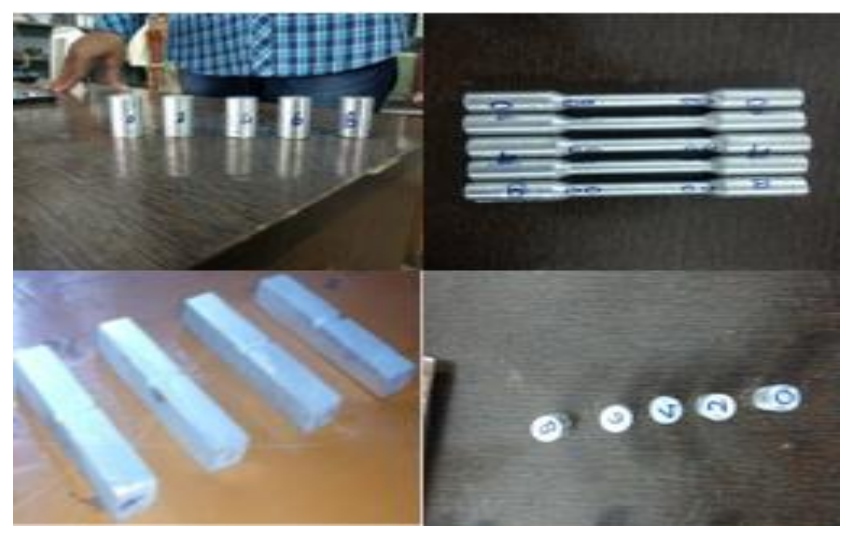

Fig 1.b Samples prepared for various tests

\section{Cold Extrusion}

Al6063 and its composites were cold impact extruded with a deformation rate of 130 $\mathrm{mm} / \mathrm{sec}$ and a punch pressure of $1.06 \mathrm{KN} / \mathrm{mm} 2$ .The extrusion ratio of the process was 1.93 with a total strain of 1.45 using a mechanical crank forging press of $800 \mathrm{~T}$ capacity, at Klass Technology Ventures Pvt.Ltd, Bangalore.The photograph of the press is shown in Fig.2.

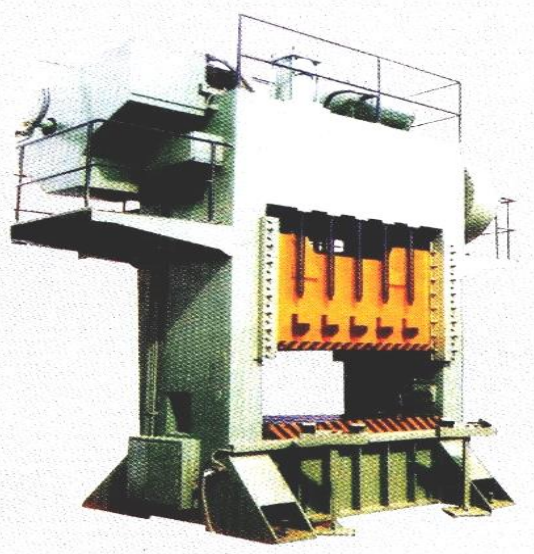

Fig.2 Photograph of Mechanical press used in the present work

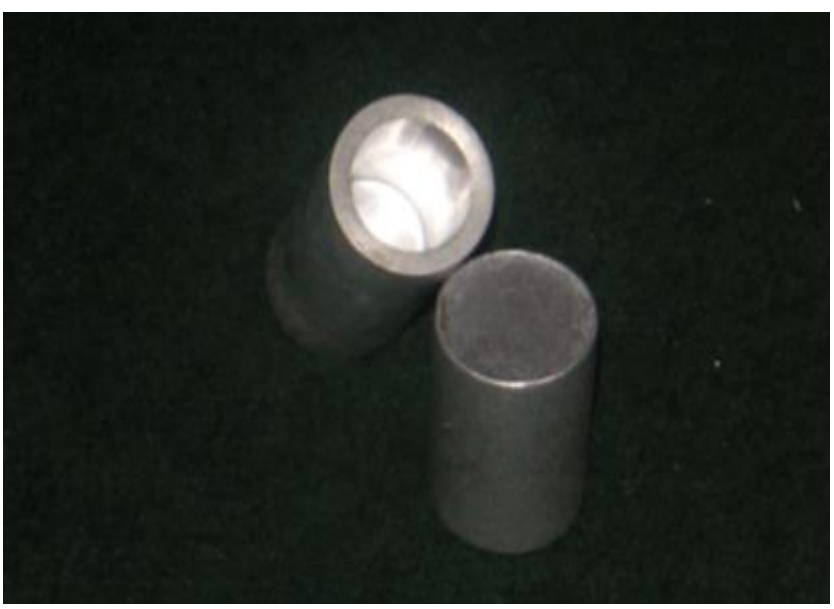

Fig.3 Photograph of Slug and extruded tube 


\section{MECHANICAL AND WEAR TESTING}

\section{A. Tensile Test}

Specimen of Al6063 matrix and its composite systems prepared according to ASTM B557M were tested for tensile test under 40 ton hydraulic universal testing machine of FIE (Fluid Instruments and Engines) made in $\mathrm{M} / \mathrm{s}$ Bharat Technical Lab. The behavior of material under tensile test reveal lot information about prepared composites.

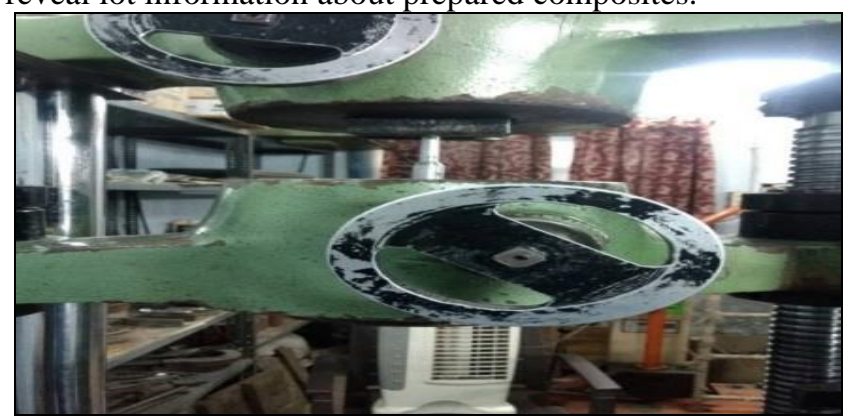

Fig 4 Specimen attached in UTM for tensile test

\section{B. Charpy Impact Test}

The specimen prepared as per IS: 1757 standard. The specimen is cut into $10 \mathrm{~mm} \times 10 \mathrm{~mm}$ cross section area and a length of $55 \mathrm{~mm}$ and a notch of $2 \mathrm{~mm}$ from top in the center of the specimen and test was conducted.

The specimen of size $55 \times 10 \times 10 \mathrm{~mm} 3$ is clamped in a support at the bottom of the machine. The notch is situated in bottom facing apposite to hammer of the arm.

\section{Hardness Test}

Vickers micro hardness tests were performed on matrix and its composite systems the micro hardness tests was conducted on the polished samples. The polished samples were subjected for micro hardness tests on Shimadzu Micro hardness tester.

\section{Adhesive wear test}

The wear test for cold extruded of both the matrix alloy and its composites system were studied on the standard pin on disc wear test rig for samples of different reinforcement studied under different loads, speed and distance. The photograph of the wear test rig is shown in Fig 5. The samples subjected for wear test was grinded with silicon carbide abrasive paper of 320 grit size. The loss of height of the samples were recorded at different intervals of time ranging from $5 \mathrm{mins}$ to $30 \mathrm{mins}$. The test was carried at constant speed of 100rpm and constant track radius of $0.20 \mathrm{~m}$ for different loads from $10 \mathrm{~N}$ to $60 \mathrm{~N}$ insteps of $10 \mathrm{~N}$.

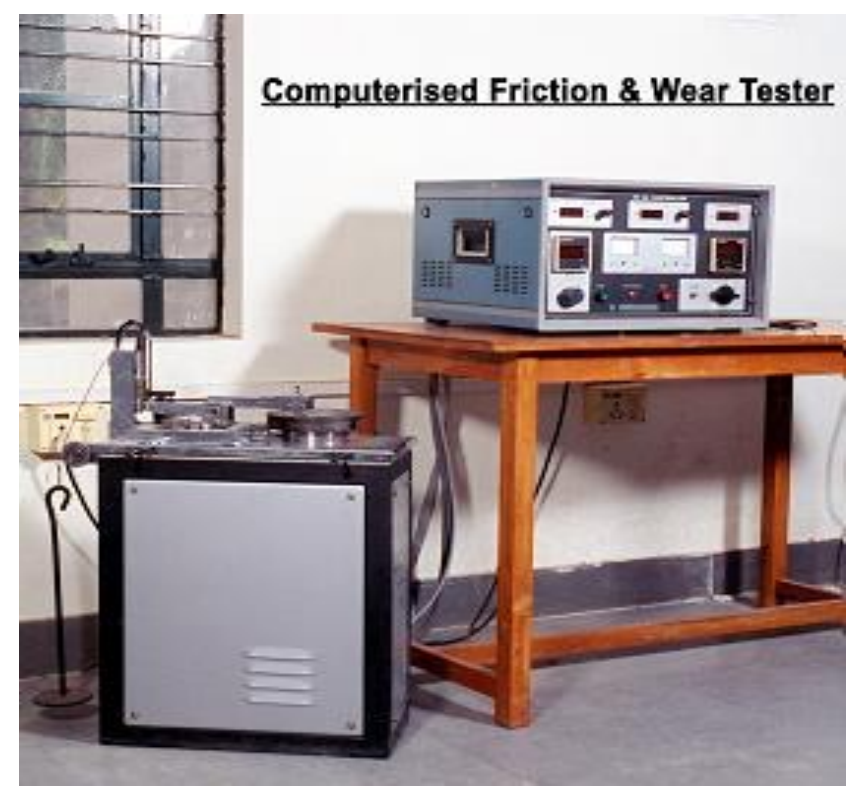

Fig 5: Computerized Pin on disc setup

\section{RESULT AND DISCUSSION}

\section{A.Vickers micro hardness}

The below represents the variation of vicker's microhardness value for all reinforcement with different weight percentage. The variation of micro hardness of cold extruded matrix alloy and its composites with increased contents of reinforcement of all systems studied are shown in Fig 6. The increase in hardness of cold extruded matrix alloy and its composites can be attributed to that during cold extrusion process the existing minor flaws and porosity in the casting was recovered during cold extrusion.

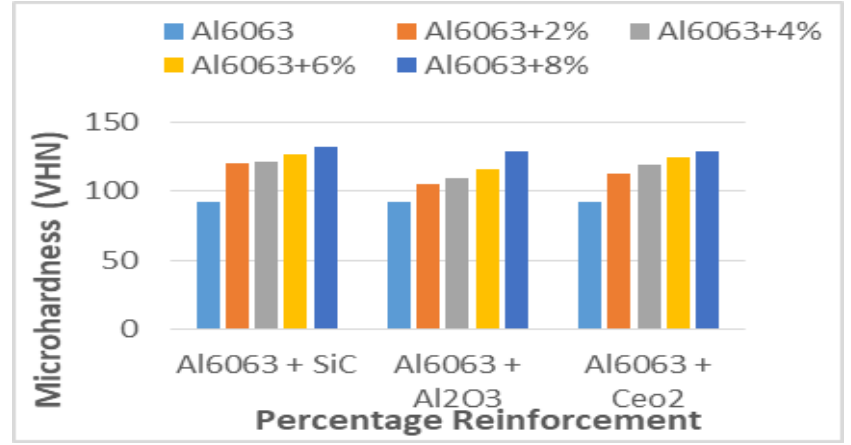

Fig 6: Variation of micro hardness with increased content of reinforcement for Cold Extruded matrix alloy Al6063 $\&$ its composites.

Further the increased hardness of cold extruded composites may be due to higher strain hardening effect of cold extrusion. Increased contents of reinforcement leads to increase in hardness for a given composite systems reinforcement studied. The hardness of matrix alloy Al6063 enhanced by $15.6 \%$ on cold extrusion. Where an improvement in micro hardness of $42.1 \%$ is observed for Al6063 + 8Wt\%SiC. The improvement in micro hardness after cold extrusion of $39.7 \%$ is observed for Al6063 + $8 \mathrm{Wt} \% \mathrm{Al}_{2} \mathrm{O}_{3}$. Whereas Al6063 $+8 \mathrm{wt} \% \mathrm{CeO}_{2}$ exhibited an improved by $38.9 \%$ on cold extrusion when compared with cast composites. 


\section{B.Tensile Strength}

Fig 7 represents the variation of ultimate tensile strength of matrix alloy and its composite systems under cold extruded process for different wt\% reinforcement and reinforcing material. The increased in tensile strength of cold extruded matrix alloy and its composites systems due to some of the existing minor flaws in the casting gets healed up.

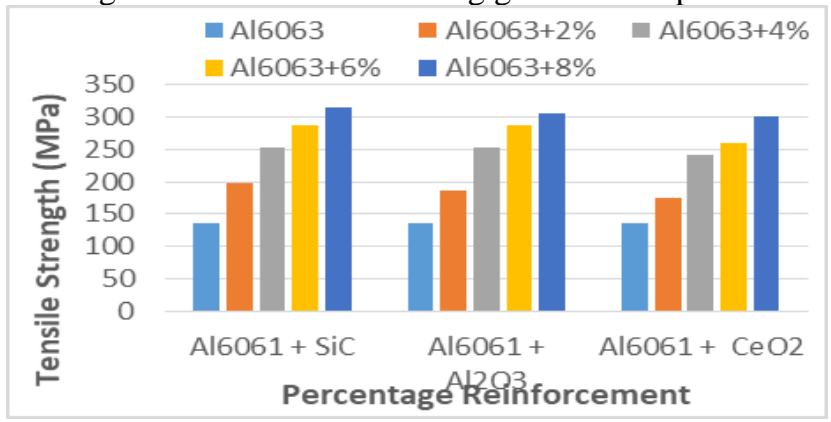

Fig. 7 - Variation of tensile strength with increase contents of reinforcement for cold extruded matrix alloy and its composites

From above figure it is observed that an improvement in ultimate tensile strength of cold extruded composites is appreciably high, when compared with matrix alloy, This drastic improvement in tensile strength value of cold extruded composites may be due the inherent brittleness exhibited by cold extrusion due to high level of residual stress that remains after cold extrusion of the matrix alloy and all the composite systems studied. The improvement in the tensile strength on cold extrusion composite with matrix alloy is about $57 \%$ for Al6063-8wt $\% \mathrm{SiC}$, where as $55.7 \%$ for Al6063-8wt $\% \mathrm{Al}_{2} \mathrm{O}_{3}$ and $55.1 \%$ for $\mathrm{Al6063-8wt \%} \mathrm{CeO}_{2}$ showed an improvement of $51.22 \%$ in tensile strength values on cold extrusion when compared with their cast counter parts.

C.Cold Extrusion of matrix alloy Al6063 and its composites

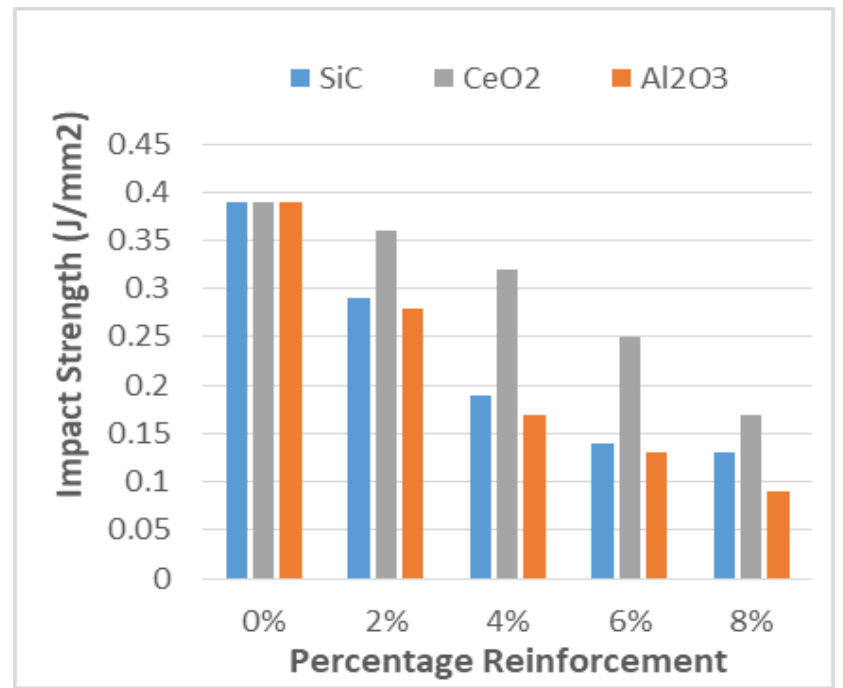

Fig 8 Variation of Impact Strength with increased contents of reinforcement of cold extruded matrix Al6061 alloy \& its composite systems.

It is observed that there is a significant reduction in the impact strength of cold extruded matrix Al6063 alloy and all the composite systems studied.
The decrease in impact strength on cold extrusion of matrix alloy is $4.8 \%$, and cold extruded composites impact strength is decreased by $25.28 \%$ for $\mathrm{Al} 60638 \mathrm{Wt} \% \mathrm{SiC}, 24.77 \%$ for $\mathrm{Al} 6063-8 \mathrm{Wt} \% \mathrm{Al}_{2} \mathrm{O}_{3}$ and $34.33 \%$ for $\mathrm{Al} 6063-8 \mathrm{Wt} \% \mathrm{CeO}_{2}$. Matrix alloy exhibits the least reduction in the impact strength values after cold extrusion (4.6\%).

\section{Adhesive wear analysis}

\section{- Effect of Reinforcement}

From the fig 9 represents the wear rate variation for cold extruded matrix alloy and its composite systems. With increase in content of reinforcement the wear rate is decreased for all the composite systems studied under cold extruded process. As hard particulate reinforcement are introduced in matrix alloy the wear resistance have improved as compared to matrix alloy and cold extruded composite systems possess low wear rate as compared to primary processed composite systems.

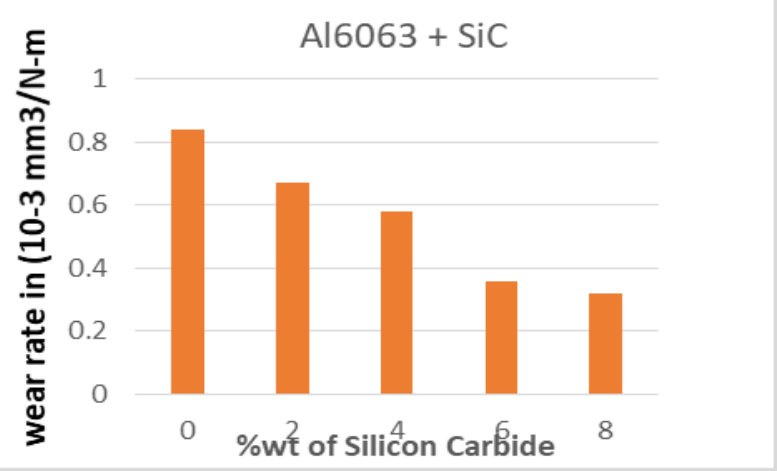

(a)

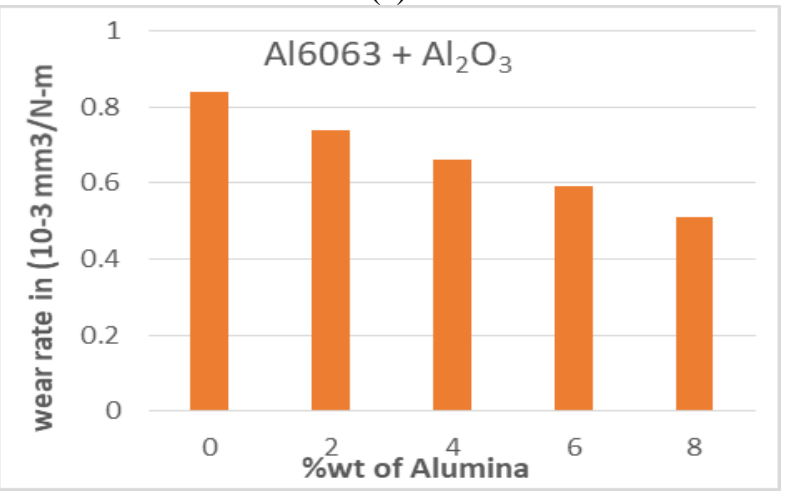

(b)

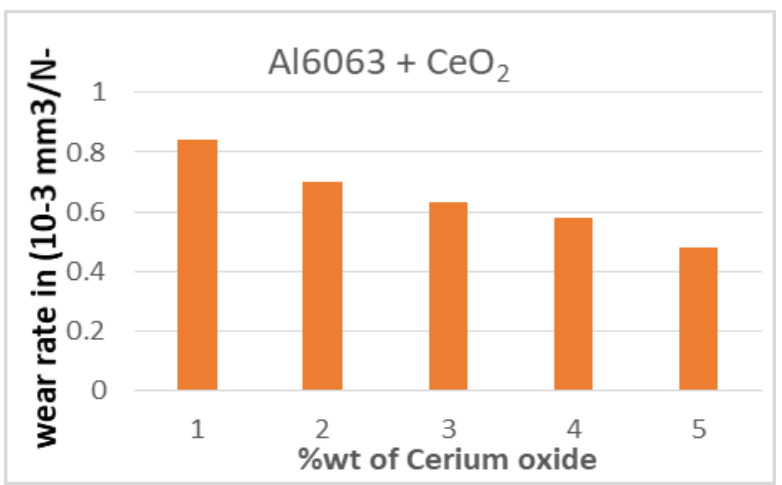

(c) 


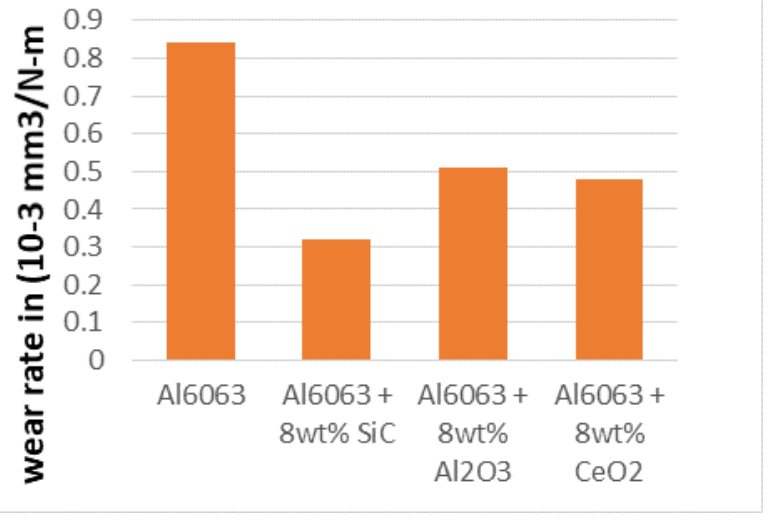

(d)

Fig.9 Effect of reinforcement on wear rate of cold extruded Al 6063 based composites

(a)Al6063+SiC (b)Al6063+ Al2O3 (c)Al6063+ CeO2 (d) Comparison of matrix alloy and $8 \mathrm{wt} \%$ of Sic, Al2O3 and $\mathrm{CeO} 2$

- Effect of load

Fig 10 represents the wear rate variation all composite systems studied and Al6063 matrix alloy under cold extruded process. As the load is increased it can be observed from figure the wear rate is linearly increased for matrix alloy and its composite systems. From the obtained results as represented in graph the with as load is increased the friction between the surfaces increased due to which the plastic deformation takes place at larger extent. It can also be attributed that due larger friction higher temperature generated of which recrystallization and grain refinement takes place and also during cold extrusion grain refinement occurs.

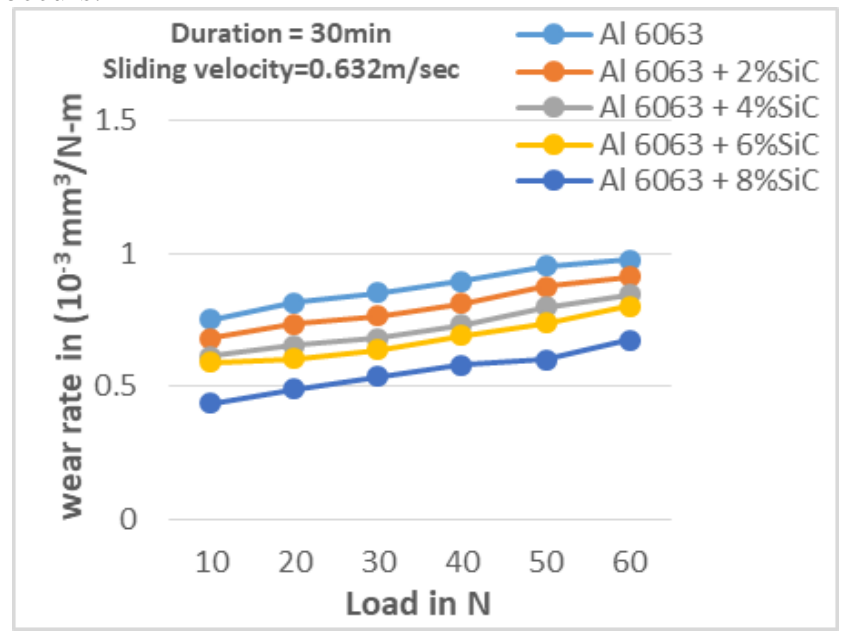

(a)

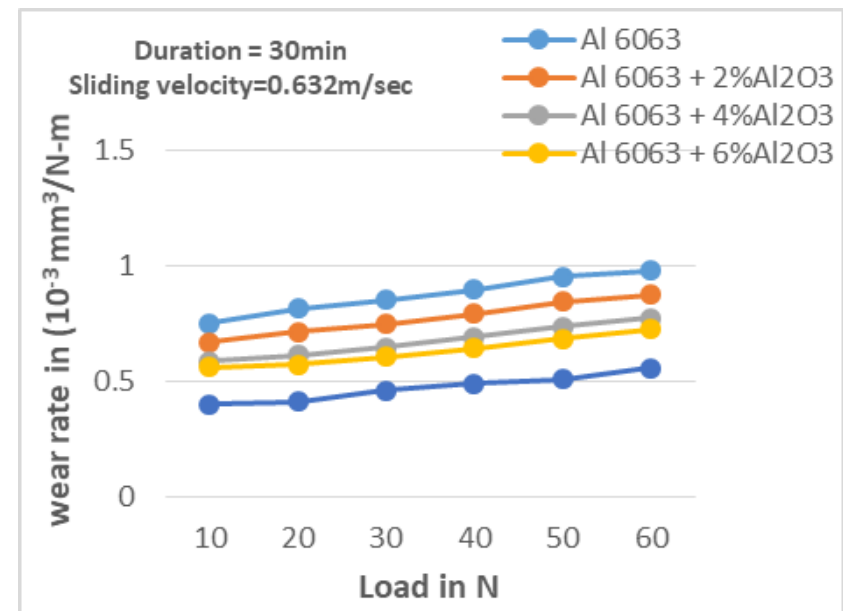

(b)

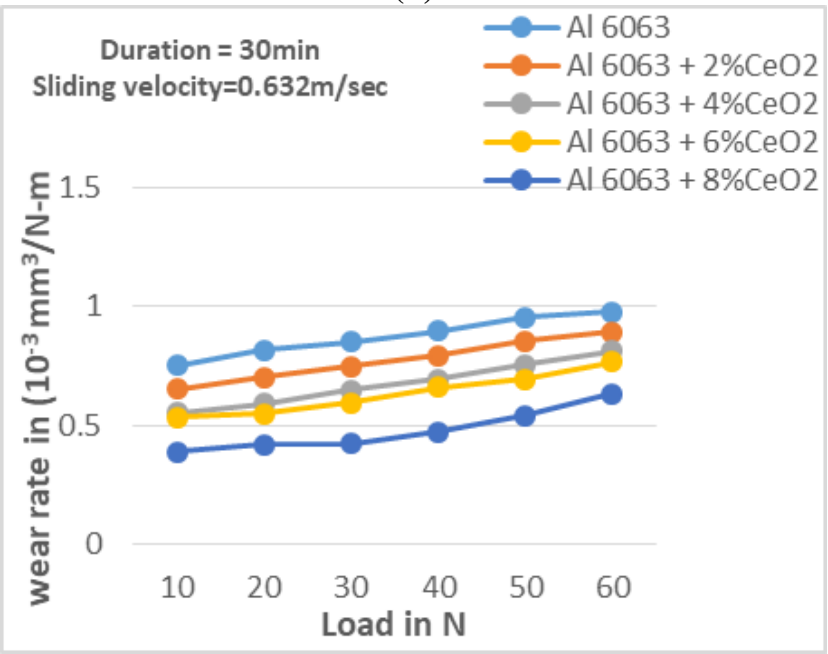

(c)

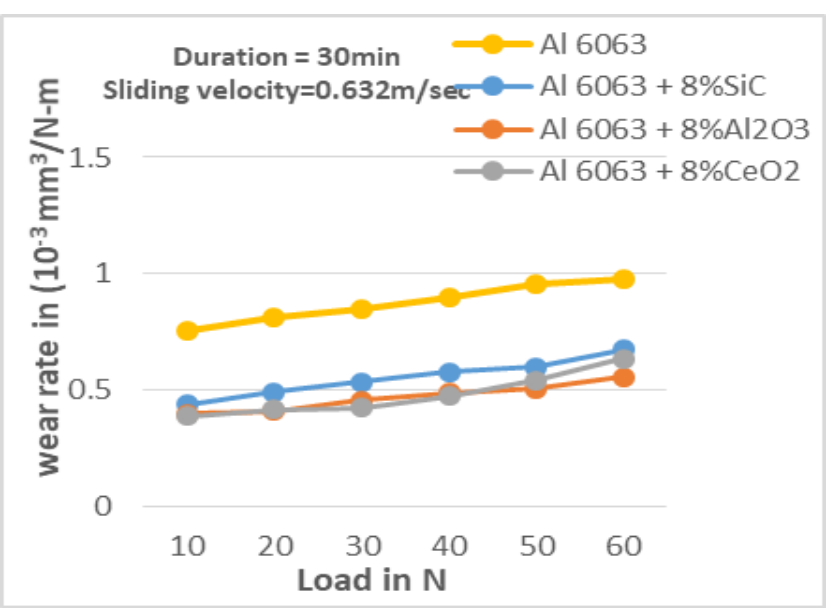

(d)

Fig.10 Dependence of wear rate of cold extruded Al 6063 matrix alloy and all its composite systems on load

(a)Al6063+SiC (b)Al6063+ Al2O3 (c)Al6063+ CeO2 (d) Comparison of matrix alloy and $8 \mathrm{wt} \%$ of Sic, Al2O3 and $\mathrm{CeO} 2$

- Effect of sliding velocity

Fig 11 shows the wear rate variation for matrix alloy and its composite systems under cold extrusion process. 
Mechanical and Wear Properties of Cold Extruded Al6063 Metal Matrix Alloy Reinforced with Silicon Carbide, Alumina and Cerium Oxide

As the sliding speed increased the wear rate also increased as it can observed from below graph. As the content for reinforcement is increased the wear rate is decreased which can be attributed reinforcing of hard particulate in soft matrix alloy, with increase in sliding velocity the surface temperature increases which damages the surface and sub surface of matrix alloy and its composite systems. Among all reinforcement studied Al6063 +SiC possess lower wear rate as compared other two reinforcement and maximum wear rate is observed for matrix alloy.

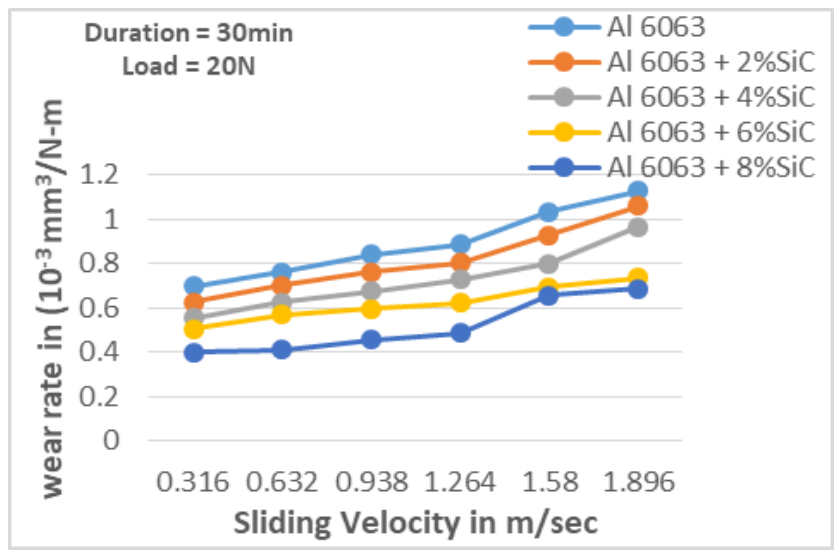

(a)

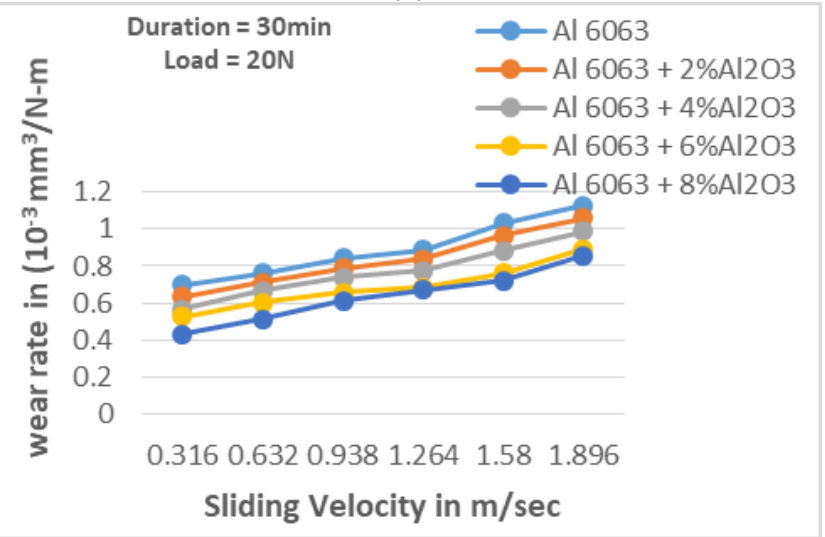

(b)

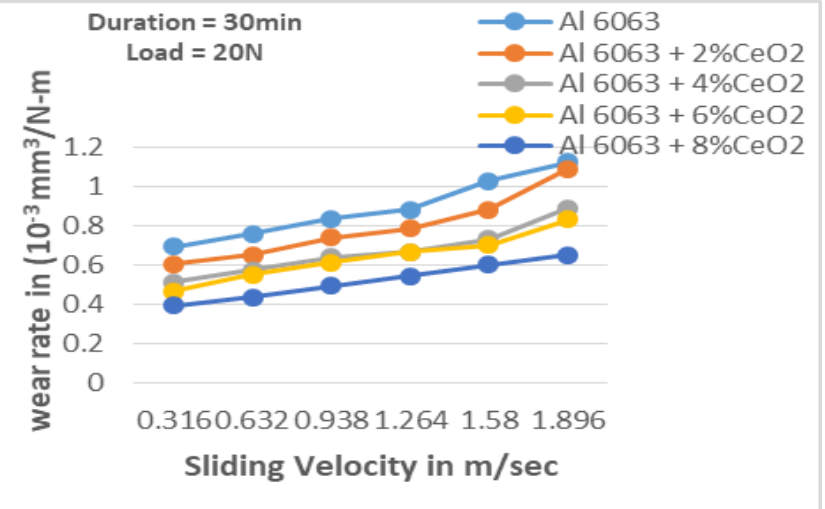

(c)

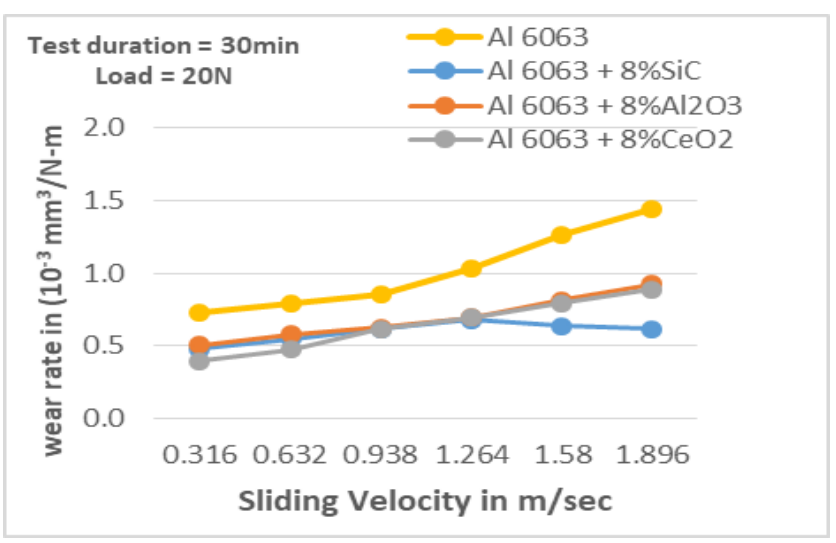

(d)

Fig.11 Dependence of wear rate of cold extruded Al 6063 matrix alloy and all its composite systems on sliding velocity

(a)Al6063+SiC (b)Al6063+ Al2O3 (c)Al6063+ CeO2 (d) Comparison of matrix alloy and $8 \mathrm{wt} \%$ of Sic, Al2O3 and $\mathrm{CeO} 2$

From Fig. 10 (d) it is evident that of all the composite systems studied $\mathrm{Al}$ 6061- $\mathrm{CeO}_{2}$ composites exhibited better wear resistance for all the sliding velocities studied. This can be attributed to higher hardness of $\mathrm{Al} 6061-\mathrm{CeO}_{2}$ composites

\section{- Effect of sliding distance}

Fig 12 represents the dependence of wear rate of matrix alloy and its composite systems studied under cold extruded process with constant sliding velocity and load with varying sliding distance. From the below graphs it can be seen as the sliding distance increses the wear rate increases for all compsite systems studied. Among all composuite studied $\mathrm{al} 6063+\mathrm{CeO}_{2}$ for $8 \mathrm{wt} \%$ has lowest wear rate. The maximum wear rate is observed for Al6063 matriz alloy

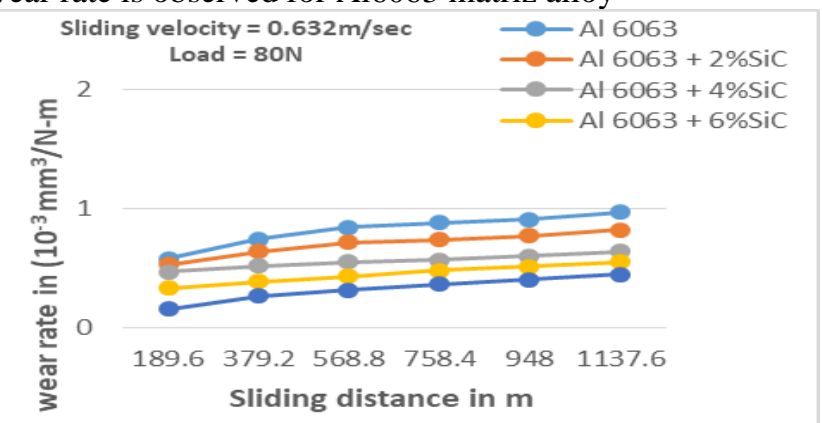

(a)

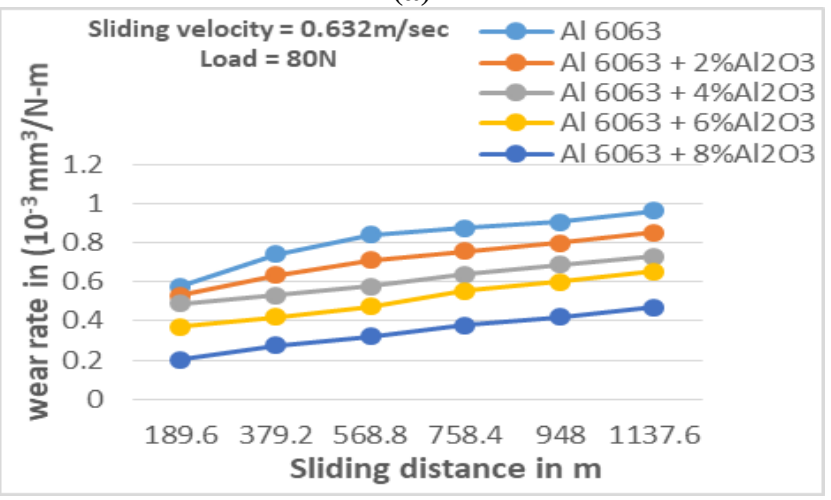

(b) 


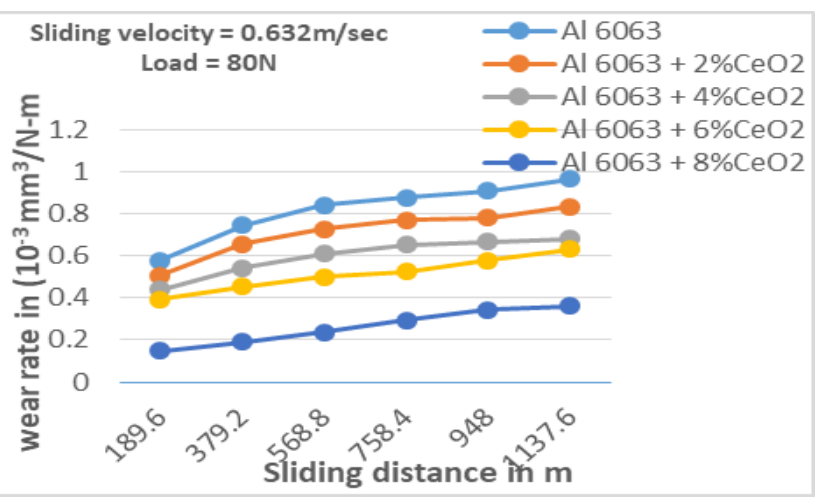

(c)

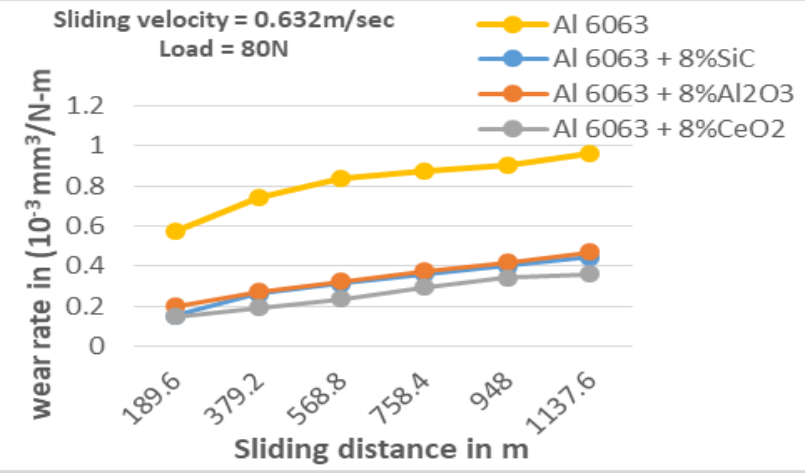

(d)

Fig.12 Dependence of wear rate of cold extruded Al 6063 matrix alloy and all its composite systems on sliding distance

(a)Al6063+SiC (b)Al6063+ Al2O3 (c)Al6063+ CeO2 (d) Comparison of matrix alloy and $8 \mathrm{wt} \%$ of Sic, Al2O3 and $\mathrm{CeO} 2$

\section{CONCLUSION}

1. $\mathrm{SiC}, \mathrm{CeO}_{2}, \& \mathrm{Al}_{2} \mathrm{O}_{3}$ have been successfully dispersed in the matrix alloy $\mathrm{Al} 6061$ by liquid metallurgy route

2. Cast Al6063-SiC, Al6061-CeO2, \& $\mathrm{Al} 6061-\mathrm{Al}_{2} \mathrm{O}_{3}$ have been successfully cold extruded

3. Cold extruded composites possess higher micro hardness, tensile strength and lower impact strength when compared with cast composites.

4. As the content of reinforcement increased the mechanical properties have increased

5. Cold extruded composites possess the lowest wear rates 4

6. Al6063-- $-\mathrm{CeO}_{2}$ possesses lowest wear rates among all the composite systems studied under identical test condition

\section{REFERENCES}

1. M.Vamsi, Krishnaa, Anthony.M.Xavior.,: 'An Investigation on the Mechanical Properties of Hybrid Metal Matrix Composites’ Procedia

2. P.V. Senthiil., Aakash, Shirrushti., 'Characterization of Aluminum Fly Ash Composites Using Stir Casting Technique'. International Journal Of Research Science \& Management,1(6) (2014)

3. P.B.Pawar., Abhay, A. Utpat., 'Development of Aluminum Based Silicon Carbide Particulate Metal Matrix Composite for Spur Gear' Procedia Materials Science 61150 - 1156 (2014)

4. Madeva, Nagaral., Bharath., V.V. Auradi., 'Effect of $\mathrm{Al}_{2} \mathrm{O}_{3}$ Particles on Mechanical and Wear Properties of 6061al Alloy Metal Matrix Composites' J Material Sci Eng, Vol-2 Issue 1 (2013)

5. Fumio Ogawa., Shuji Yamamoto.,Chitoshi.Masuda., 'Thermal Conductivity and Tensile Properties of Carbon Nanofiber-Reinforced Aluminum-Matrix Composites Fabricated via PowderMetallurgy: Effects of Ball Milling and Extrusion Conditionson Microstructures Engineering 97918 - 924 (2014)

and Resultant Composite Properties'.The Chinese Society for Metals and Springer-Verlag GmbH Germany, part of Springer Nature 2018

6. Manoj, Kumar, Yadav, Bijender, Saini., Ashu, Yadav., 'Experimental Analysis of Mechanical Properties of A16063 and SIC Composite' International Journal of Mechanical and Industrial Technology Vol 3, Issue 1, pp: 221-227 (2015)

7. Johny,James.S, Venkatesan.K., Kuppan,P., Ramanujam,R., Hybrid Aluminum Metal Matrix Composite Reinforced With SiC and TiB2 Procedia Engineering 97 ( 2014 ) 1018 - 1026 (2014).

8. B. Rajeswari, K. S. Amirthagadeswaran, K. Anbarasu., 'Investigation on mechanical properties of aluminium 7075-Silicon carbidealumina hybrid composites using taguchi method'. Australian journal of mechanical engineering, 13 (2015), 127-135,

9. T.A.Md., A.Ansari., S.Arif., Md.N.Alam., 'Mechanical properties and morphology of aluminium metal matrix nanocomposites - stir cast products'. adavances in materials and processing technologies, (2017) $1-15$,

10. K.Hemalatha., V. S. K.Venkatachalapathy., N.Alagumurthy., 'Processing and Synthesis of Metal Matrix Al 6063/Al2o3 Metal Matrix Composite by Stir Casting Process' Int. Journal of Engineering Research and Applications Vol. 3, Issue 6, pp.1390-1394 (2013)

11. K.R.Padmavathi., Dr. R.Ramakrishna., 'Tribological behaviour of Aluminium Hybrid Metal Matrix Composite’ Procedia Engineering 97 $660-667$ (2014)

12. N. Ashok, P. Shanmughsundaram., 'Effect of particles size on the mechanical propeties of SiC - Reinforcement aluminium 8011 composites'. Material Technology,51(2017) 4, 667-672,

13. Z.F Zhang., L.C Zhang., Y.W Mai., "Wear of ceramic particle-reinforced metal matrix composite", Journal of material science, Vol-30 pp 1961-1966 (1994)

14. Mohanakumar., K.C Rajashekar, H., "Development and Mechanical Properties of SiC reinforced cast and Extruded Al based metal matrix Composite", Procedia Materials Science 5934 -938 (2014)

15. Satya,Kumar, Dewangan., Dr. Arun, Arora., "Mechanical Properties of Aluminum 6063 Alloy based Graphite Particles Reinforced Metal Matrix Composite", IJSRD - International Journal for Scientific Research \& Development| Vol-3, Issue 05, (2015)

16. H.H. Kim., J.S.S. Babu., C.G. Kang., 'Hot Extrusion of A356 Aluminum Metal Matrix Composite with Carbon Nanotube/Al2O3 Hybrid Reinforcement'. Metallurgical And Materials Transactions A Volume 45a, May 2014-2645.

17. M. Sambathkumar, P. Navaneethakrishnan, K. Ponappa, KSK. Sasikumar, Mechanical and corrosion behaviour of A7075 (hybrid) metal matrix composites by two step stir casting process, Latin american journal of solids and structures, 14 (2017), 243-255,

18. S. T. Mavhungu, E. T. Akinlabi, M. A. Onitiri, F. M. Varachia, Aluminium matrix composites for industrial use: Advances and trends, Sciencedirect Procedia manufacturing, 7 (2017), 178-182,

19. C. Kannan, R. Ramanujam, Comparative study on the mechanical and microstructural characterisation of AA7075 nano and hybric nanocomposites produced by stir and queeze casting, Journal of Advanced Research, 8 (2017), 309-319,

20. Abdulhaqq A. Hamid, P.K. Ghosh, S.C. Jain, Subrata Ray, The influence of porosity and particles content on dry sliding wear of cast in situ $\mathrm{Al}(\mathrm{Ti})-\mathrm{Al}_{2} \mathrm{O}_{3}\left(\mathrm{TiO}_{2}\right)$ composite, Wear 265, 1-2, (2008) 25, 4-26,

\section{AUTHORS PROFILE}

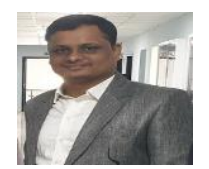

Abdul Nazeer, Research Scholar at Ghousia college of engineering, Visvesvaraya technological university. He graduated B.E (Mechanical Engineering) in 2008 and M-Tech (Machine Design) in 2011 Visvesraya Technological university Belgavi, He has 09 years of teaching experience and published 07 journals paper and 01 conference paper. His research interest metal matrix composite

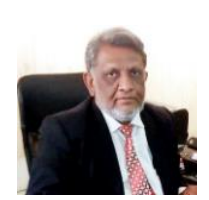

Dr. Mir Safiulla, specialized in areas of Composite Materials, Metal Forming. Manufacturing Processes \& Technology, Automotive Engineering, Management and Maintenance Engineering. B.E. (Mechanical), Mysore University, Mysuru. M.E. (Metal Casting Science \& Eng), Bangalore University, Bengaluru. Ph.D. (Composite Materials), Visvesvarya Technological University, Belagavi. He has 35 Years of Teaching, Research and Administration with 89 publication in national and international journals and 45 publication in conferences and Conferences Conducted: 44. 